\title{
Refractory Malignant Pharyngeal Neoplasm
}

National Cancer Institute

\section{Source}

National Cancer Institute. Refractory Malignant Pharyngeal Neoplasm. NCI Thesaurus.

Code C150532.

Malignant pharyngeal neoplasm that is resistant to treatment. 